\title{
Planar slow-wave structures for miniaturized low-voltage Cherenkov devices
}

\author{
N.M. Ryskin, ${ }^{1,2}$ A.I. Benedik, ${ }^{1}$ A.G. Rozhnev, ${ }^{1,2}$ N.I. Sinitsyn, ${ }^{2}$ G.V. Torgashov, ${ }^{2}$ R.A. Torgashov ${ }^{1,2}$ \\ ${ }^{1}$ Saratov State University, Saratov, Russia, ryskinnm@info.sgu.ru \\ ${ }^{2}$ Saratov Branch, Institute of Radio Engineering and Electronics, Saratov, Russia
}

\section{Introduction}

Microfabricated vacuum power amplifiers and oscillators operating at $\mathrm{THz}$ frequencies have attracted a great interest. Among them, linear-beam Cherenkov devices such as travelling-wave tubes (TWT) and backward-wave oscillators (BWO) have been actively studied. For miniaturized devices, a possibility of low-voltage operation is of primary importance, since decrease of voltage allows reduce of size and weight of the device. In particular, promising planar slow-wave structures (SWSs) utilizing a metallized meander mi-crostrip line on a dielectric substrate has been proposed [1]. Later, similar SWSs have been considered in [2-4].

In this paper, we present the results of numerical simulation, fabrication, and cold measurement of the microstrip meander-line and interdigital SWSs. Schematics of the SWSs are shown in Fig. 1(a) and Fig. 1(b), respectively. Fig. 1(c) shows qualitative drawing of their dispersion diagrams. One can see that the meander and interdigital SWS are suitable for TWT and BWO operation, respectively. The proposed structures exhibit high slowdown factor that is profitable for low-voltage operation.

\section{G-band meander-line SWS}

We have developed the meander-line SWS at G-band (180-230 GHz) [5, 6]. For the fabrication, copper films with $1 \mu \mathrm{m}$ thickness were sputtered over quartz and polycor substrates. After that, the structure was patterned by photolithography. Below the metallic layer, there is a dielectric pedestal, which height $g$ is regulated by the etching time. Dimensions of the SWS are listed in the Table 1.

Basic electromagnetic parameters of the designed meander SWS were calculated. It is assumed that the structure is placed inside a rectangular waveguide, which is not shown in Fig. 1. In Fig. 2(a), dispersion diagram is plotted. One can see that the SWS passband is rather wide. The SWS exhibits normal dispersion with slowwave factor $c / v_{p h} \sim 7 \div 11$ in the operating frequency range $180-230 \mathrm{GHz}$. The beam synchronism voltage is as low as $3 \div 5 \mathrm{kV}$.

Pierce coupling impedance $R_{c}$ vs. frequency is shown in Fig. 2(b). In the simulation, it is supposed that a $180 \times 30 \mu \mathrm{m}^{2}$ sheet electron beam propagates at distance $h$ over the metallized strip surface. In Fig. 2(a), the coupling impedance averaged over the beam cross-section is plotted at different values of $h$. The coupling impedance rapidly decreases with the increase of $h$, because the electromagnetic field decays exponentially in vertical direction. Nevertheless, $R_{c} \sim 1 \div 10 \mathrm{Ohm}$ is attained in the 180$230 \mathrm{GHz}$ frequency range for $h \sim 20 \div 50 \mu \mathrm{m}$.

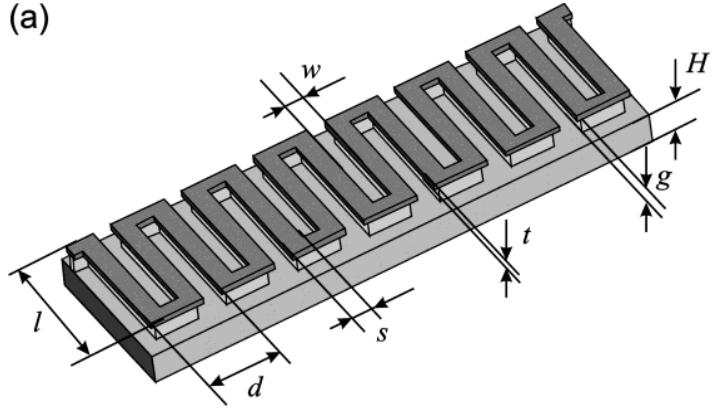

(b)

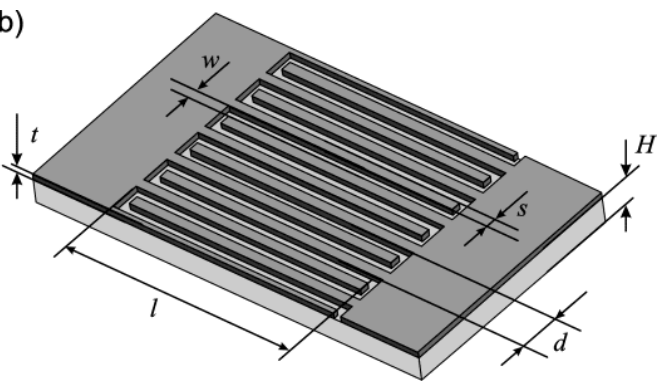

(c)

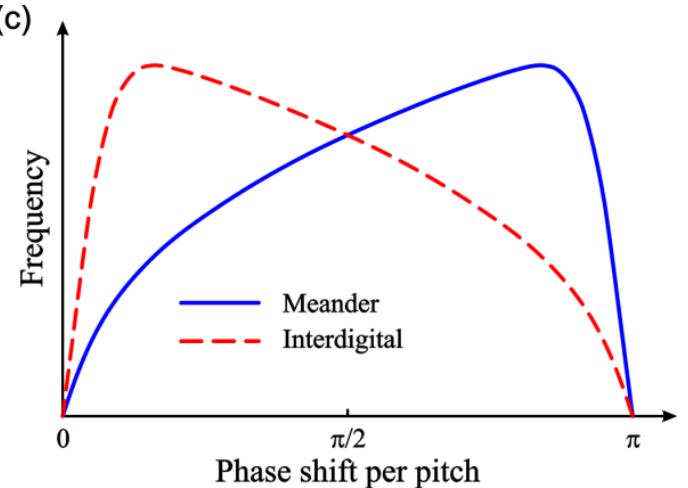

Fig. 1. Schematic diagrams of meander $(a)$ and interdigital (b) planar SWSs, and qualitative dispersion diagrams (c)

Table 1

\begin{tabular}{|l|l|}
\hline Waveguide cross section, $a \times b(\mathrm{~mm})$ & $2 \times 1$ \\
\hline Substrate thickness $H(\mu \mathrm{m})$ & 500 \\
\hline SWS period, $d(\mu \mathrm{m})$ & 50 \\
\hline Meander width $l(\mu \mathrm{m})$ & 200 \\
\hline Metallized strip width, $s(\mu \mathrm{m})$ & 15 \\
\hline Metallized strip thickness, $t(\mu \mathrm{m})$ & 1 \\
\hline
\end{tabular}

\section{V-band meander and interdigital SWSs}

Due to the limited capability for cold-test measurements in G-band, we turned to the study of lowerfrequency V-band (50-70 GHz) prototype SWSs. Several samples of the meander and interdigital SWS circuits with input/output couplers on quartz and polycor substrate were fabricated. 

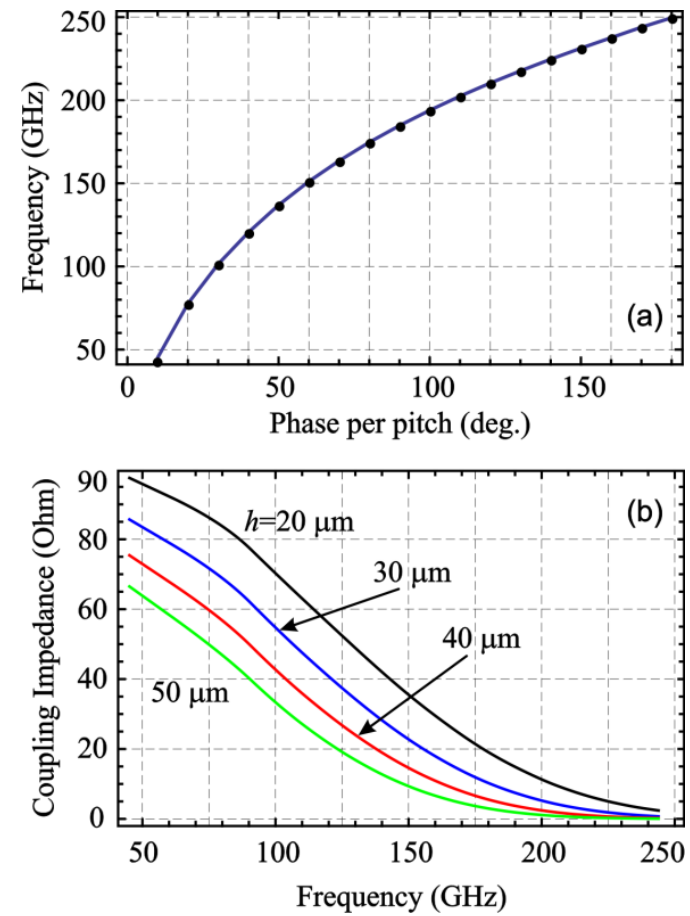

Fig. 2. Dispersion diagram (a) and interaction impedance (b) for the G-band meander-line SWS

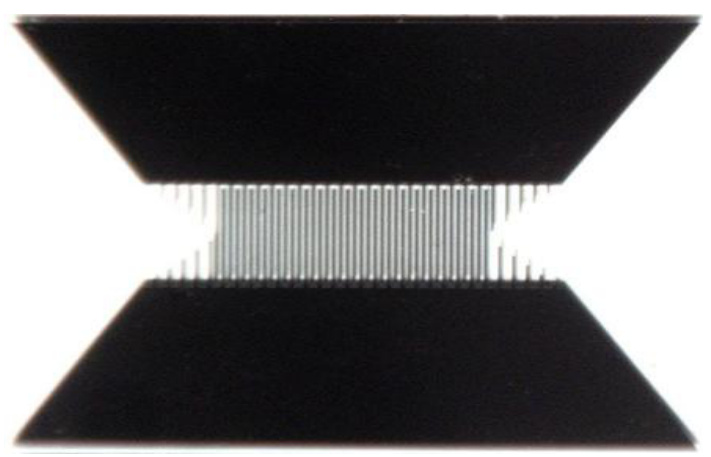

Fig. 3. Photo of the V-band interdigital SWS

In Fig. 3, photo of the interdigital SWS is shown. The SWS consists of 20 periods. Matching sections with linear decrease of pin height are placed at both ends. Dimensions of the SWS are listed in the Table 2. The SWS has anomalous dispersion and exhibits high slow-wave factor $c / v_{p h} \sim 10 \div 30$. The corresponding synchronism voltage is $1 \div 3 \mathrm{kV}$. Coupling impedance $R_{c} \sim 1 \div 10 \mathrm{Ohm}$ is calculated for a $500 \times 50 \mu \mathrm{m}^{2}$ sheet electron beam propagating at distance $h=50-75 \mu \mathrm{m}$ over the metallic surface.

$S$-parameters of the circuit were measured using the two-port P2-69 scalar network analyzer in 53.57-78.33 $\mathrm{GHz}$ frequency band. For the measurements, the SWSs were placed in the $3.6 \times 1.8 \mathrm{~mm}^{2}$ waveguide. In the coldtest measurements, VSWR less than 2 and transmission losses less than $5 \mathrm{~dB}$ were observed.
The meander SWS exhibits normal dispersion in the $50 \div 70 \mathrm{GHz}$ frequency range. For the SWS on silica substrate, beam synchronism voltage is $3 \div 5 \mathrm{kV}$.

Table 2

\begin{tabular}{|l|l|l|}
\hline Substrate material & Quartz & Polycor \\
\hline Waveguide cross section $(\mathrm{mm})$ & $3.6 \times 1.8$ & $3.6 \times 1.8$ \\
\hline SWS period, $d(\mu \mathrm{m})$ & 100 & 100 \\
\hline Pin length, $l(\mu \mathrm{m})$ & 825 & 575 \\
\hline Pin width, $s(\mu \mathrm{m})$ & 25 & 25 \\
\hline Etched strip width, $w(\mu \mathrm{m})$ & 25 & 25 \\
\hline Metallized strip thickness, $t(\mu \mathrm{m})$ & 1 & 1 \\
\hline Substrate thickness, $h(\mu \mathrm{m})$ & 500 & 500 \\
\hline
\end{tabular}

\section{Summary}

In conclusion, planar SWSs on dielectric substrates possess wide bandwidth and relatively large slow-wave factor. They are suitable for low-voltage millimeter and THz-band Cherenkov devices such as TWT and BWO with sheet electron beam. Several samples of SWSs in Gand V-band were designed, simulated and fabricated. Good transmission characteristics were measured.

This work is supported by the Russian Science Foundation grant No. 17-12-01160.

\section{References}

1. Gulyaev, Y.V., Zhbanov, A.I., Zakharchenko, Y.F., Nefedov, I.S., Sinitsyn, N.I., Torgashov, G.V. Planar slow wave structures of miniature electrovacuum microwave devices // J. Comm. Technol. Electron., 1994. V. 39, No. 12. P. 2049-2058.

2. Sengele, S., Jiang, H., Booske, J.H., Kory, C.L., van der Weide, D.W., Ives, R.L. Microfabrication and characterization of a selectively metallized W-band meander-line TWT circuit // IEEE Trans. Electron Devices. 2009. V. 56, No. 5. P. 730-737.

3. Shen, F. Wei, Y.-Y., Xu, X., Liu, Y., Yin, H.-R., Gong, Y.B., Wang W.-X. 140-GHz V-shaped microstrip meander-line traveling wave tube // J. Electromagn. Waves Appl. 2012. V. 26, No. 1. P. 89-98.

4. Sumathy, M., Augustin, D., Datta, S.K., Christie, L., Kumar L. Design and RF characterization of W-band meanderline and folded-waveguide slow-wave structures for TWTs // IEEE Trans. Electron Devices. 2013. V. 60, No. 5. P. 17691775 .

5. Benedik, A.I., Rozhnev, A.G., Ryskin, N.M., Torgashov, G.V., Sinitsyn, N.I., Bushuev, N.A., Shalaev P.D. Study of electrodynamic parameters of the planar meander slow-wave structures for $\mathrm{THz}$ band traveling wave tubes // Abstracts of the Sixteenth IEEE International Vacuum Electronics Conference (IVEC2015), Beijing, China, April 27-29, 2015.

6. Karetnikova, T.A., Benedik, A.I., Rozhnev, A.G., Rys-kin, N.M., Torgashov, G.V., Sinitsyn, N.I., Shalaev P.D. Development and modeling of G-band vacuum tube power amplifiers with sheet electron beam // 41st International Conference on Infrared, Millimeter, and Terahertz Waves (IRMMW-THz), Copenhagen, Denmark, 2016. 